\title{
Surveys in Geophysics
}

\section{Constrained regional recovery of continental water mass time-variations from GRACE- based geo-potential anomalies \\ --Manuscript Draft--}

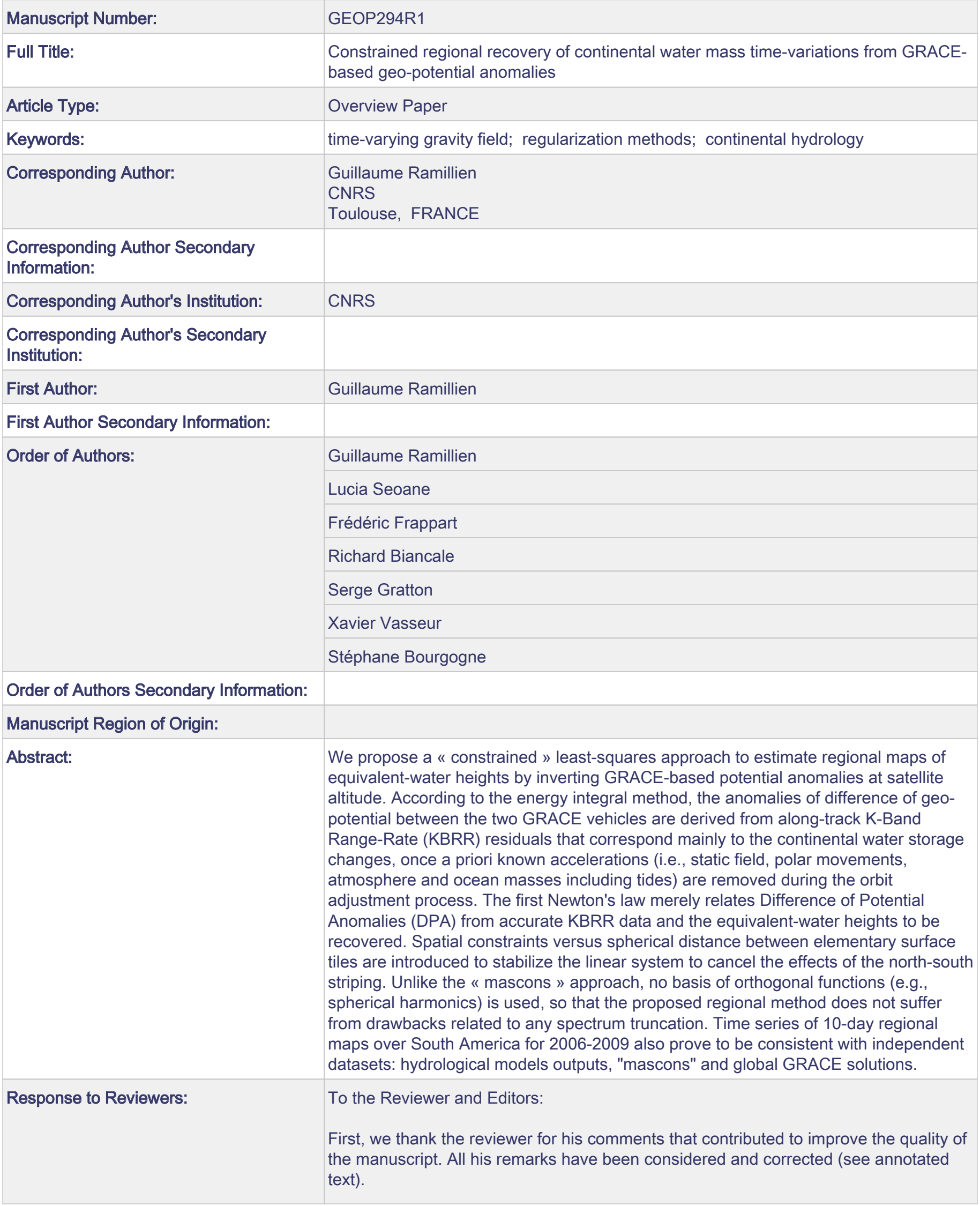


The document has also benefit from slight corrections in second readings of my coauthors.

In particular:

* Paragraph 1.2.3, page 6: The text part presenting the GRACE-based ICA solutions has been re-written to clarify how they are computed, and which ones are used for comparison with the regional solutions for South America. As mentioned in the text, more details on ICA of the monthly GRACE solutions can be found in Frappart et al., (2010) and Frappart et al., (2011).

* Loading effects, page 8: a new sentence has been added to precise that elastic compensation can be in the regularization as Legendre polynomials, and thus elastic Love numbers, are introduced. This point is also referred to Eq.24 from Ramillien et al., (2011).

* Eq.11, page 10: we agree the definition of Bi,j for the cases 3 and 4 was completely wrong, so that it is now corrected with new formula, as it is now mentioned in the revised document.

* Spherical harmonics, page 12: Spherical harmonics. We agree about the fact that north-south striping is not only due to the mode of representation in spherical harmonics, but the orbit configuration and time aliasing of short-term phenomena as well. This ambiguous sentence has been simply removed from the text and replaced by the explanation provided by the reviewer.

* Explanation of acronym "MOY" is now given in Eq.11a, page9, and this latter equation is mentioned in the caption of the Figure 3.

--- End of document --- 
1 Constrained regional recovery of continental water mass time-variations from GRACE-

2

3

4

5

6 Vasseur (5), S. Bourgogne (6)

7

8 (1) Université de Toulouse, UPS, OMP, GET, Toulouse, France.

9 (2) CNRS, OMP, GET, Toulouse, France.

10 (3) CNES, OMP, GET, Toulouse, France.

11 (4) IRIT, INP, Toulouse, France.

12 (5) CERFACS, Toulouse, France.

\section{based geo-potential anomalies}

(6) NOVELTIS, Toulouse, France.

\section{Submitted to ed to-Surveys in Geophysics}

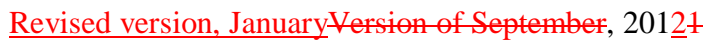

Corresponding author:

G. L. Ramillien

GRGS - Observatoire Midi-Pyrénées (OMP)

14, Avenue Edouard Belin

31400 Toulouse - France

Phone: (+33) 0561332970

E-mail: ramillien@ get.obs-mip.fr 


\section{Abstract}

3 We propose a «constrained » least-squares approach to estimate regional maps of equivalent4 water heights by inverting GRACE-based potential anomalies at satellite altitude. According 5 to the energy integral method, the anomalies of difference of geo-potential between the two 6 GRACE vehicles are derived from along-track K-Band Range-Rate (KBRR) residuals that 7 correspond mainly to the continental water storage changes, once a priori known 8 accelerations (i.e., static field, polar movements, atmosphere and ocean masses including tides) are removed during the orbit adjustment process. The first Newton's law merely relates Difference of Potential Anomalies (DPA) from accurate KBRR data and the equivalent-water heights to be recovered. Spatial constraints versus spherical distance between elementary surface tiles are introduced to stabilize the linear system to cancel the effects of the nNorths South striping. Unlike the «mascons » approach, no basis of orthogonal functions (e.g., spherical harmonics) is used, so that the proposed regional method does not suffer from drawbacks related to any spectrum truncation. Time series of 10-day regional maps over the South America for 2006-2009 also prove to be consistent with independent datasets: hydrological models outputs, "mascons" and global GRACE solutions.

\section{INTRODUCTION}

Since its launch in March 2002, the Gravity Recovery and Climate Experiment (GRACE) mission provides a global mapping of the variations in time and space of the Earth's gravity field (Tapley et al., 2004a; Tapley et al., 2004b; Schmidt et al., 2006). The originality of this geodetic mission is to measure very accurately the distance (and velocity) variations between two co-orbiting vehicles named A and B, using a line-of-sight K-Band Range-Rate (KBRR) of a precision of $\sim 0.1 \mu \mathrm{m} / \mathrm{s}$ or equivalently $10 \mu \mathrm{m}$ after integration versus time. Consequently, the level of precision of this system enables for the first time the detection of gravity signatures of mass redistributions inside the fluid envelops of our planet.

Three official processing centers forming the Science Data Center, Center for Space Research at University of Texas (UTCSR), Austin, TX, USA; GeoForschungsZentrum (GFZ), Potsdam, Germany; Jet Propulsion Laboratory (JPL), Pasadena, CA, USA, routinely use the positions, velocities and accurate KBR data (i.e., Level-1 GRACE parameters) to produce monthly global fields developed in "Stokes" coefficients (i.e., spherical harmonics of the geopotential) after correction of known a priori mass variations via models: atmosphere, 
barotropic ocean and tides (solid Earth, ocean and pole). These Level-2 residuals should

reflect the sum of noise, errors in the correcting gravity models, non modelled phenomena,

which is mainly the time-varying continental hydrology component of the total gravity field measured from space.

The measured gravity signals also contain "errors" with respect to the correcting models for the ocean tides, especially over poles, and atmosphere and ocean mass, but with magnitudes smaller than the primary hydrology signal and at various temporal frequencies. Unfortunately, due to the resonance of orbits, important short-wavelength north-south striping effects deteriorate the Level-2 global solutions, and thus require post-processing low-pass filtering before any geophysical exploitation. Systematic correlated errors associated with the incomplete modelling of relatively well-known mass variations to resonant orders of monthly mean spherical harmonics have been reported by Han et al. (2004). Significant degradation of the monthly global solutions have been reported by Wagner et al. (2006), due to sparse repeat tracks of 61/4 (rev/day) of the GRACE orbits in deep orbit resonance.

Various spatial smoothing techniques were developed to mitigate optimally the ill-determined harmonic coefficients of higher degrees and orders (Wahr et al., 1998; Davis et al., 2004; Han et al., 2005; Ramillien et al., 2005; Swenson and Wahr, 2006; Chen et al., 2006; Kusche, 2007). The post-processed Level-2 monthly solutions have been largely used to study mass balance of recently evolving hydrological systems in different regions, such as large river basins (Tapley et al., 2004), ice fields (Velicogna and Wahr, 2006) and oceans (Chambers et al., 2004; Zlotnicki et al., 2007). A review of important results based on Level-2 GRACE products for continental hydrology can be found in Ramillien et al. (2008).

Alternatively, the "mascons" approach consists of solving a linear combination of spherical harmonics of surface elements, instead of solving individual spherical harmonic coefficient globally (Rowlands et al., 2005). This method uses inherently constraints among the coefficients that are dependent on geographical locations. Han et al. (2005) use downward continuation of the in situ geopotential difference that is pre-determined from the satellite tracking data analysis. Both methods demonstrated enhancement of the solutions in space and time for recovering the time-varying regional gravity field. So far, no spherical harmonics approach for mass flux deviation from GRACE has been able to produce that type of both spatial and time resolution.

Numerous developments have been made on regional methods (Lemoine et al., 1998; Jekeli, 1999; Garcia, 2002; Han et al., 2003, 2004, 2005; Rowlands et al., 2002, 2005, 2010; Luthcke et al., 2006). For example, 10-day resolution mascons revealed each year's distinct meltings 
and accumulations (Luthcke et al., 2006), and resolution of 2 degrees over individual glaciers (Luthcke et al., 2008). Besides, the mascons approach has revealed more information about interannual variability in the subregions than any Stokes coefficients-based approach (Luthcke et al., 2008). Global and mascons methods based on spherical harmonics have provided very similar results for the mass trend in the drainage basins, especially when no spatial constraints are taken into account (Rowlands et al., 2010).

Spherical harmonics-based methods are band-limited in the spectral domainspace, thus they suffer from errors of spectrum truncation, so that recovered signals remain quite smooth, and it generates spatial leakage of energetic signals everywhere on the terrestrial sphere.

Instead of considering another spherical harmonics-type approach, we propose here to invert regionally the linear Newtonian operator plus a constraint matrix for regularization, in order to estimate the time-variations of water mass over continents with no striping. Compared to the previous Singular Value Decomposition (SVD) method proposed by Ramillien et al. (2011) where the choice of the regularization parameter is made by L-curve analysis, the solution of the normal equations is here stabilized by adding geographical constraints (i.e., correlation coefficients between equivalent-water heights) which are physically-much meaningful. The originality of the study is that the solution does not depend on global smoothing orthogonal functions (i.e., band-limited spherical harmonics), but on estimating directly equivalent-water heights of discrete surface elements. This study will have the following structure. First, we present the GRACE-based data we used for water mass change estimation. Secondly, the methodology is presented to explain: (1) how KBRR residuals are converted into along-track potential difference anomalies following the energy integral method; (2) the regularization of the Newtonian operator using geographical constraints of different types (i.e., exponential, Gaussian, uniform) and lengths. Regional solutions are also computed for elementary surfaces of various resolutions (e.g., 1, 2 or 4 degrees). Thirdly, the error analysis of the predicted estimates is made using potential difference simulations, especially by adding random noise in the data to be inverted. Finally, the proposed constrained regional method is applied to produce time series of regional water mass change over South America for demonstration of its feasibility. Amplitudes of these regional solutions are compared to GRACE-based products and independent datasets for validation at least for the seasonal cycle.

\section{Data used in this study}




\subsection{GRACE-based KBRR residuals}

The Géodésie par Intégrations Numériques Simultanées (GINS) satellite orbitography software developed by the GRGS/CNES in Toulouse, France, has been used for least-squares orbits adjustment from a priori model accelerations, and thus KBRR data reduction. GRACE data have been reduced in 24-hour arcs and processed covering the complete years 2006 and 2009. The a priori gravitational force models applied to the GRACE vehicles A and B for numerical orbit integration have been: (1) a static gravity field model EIGENGRGS.RL02.MEAN-FIELD to order and degree 160; (2) 3D body perturbations DE403 of Sun, Moon and six planets (Standish et al. 1995); (3) solid Earth tides IERS conventions 2003 (McCarthy and Petit 2003); (4) solid Earth pole tide IERS conventions 2003; (5) oceanic tides FES2004 to degree and order 100 (LeProvost et al. 1994); (6) oceanic pole tide from Desai model (Desai 2002); (7) atmospheric pressure model ECMWF 3-D grids per 6 hours and (8) oceanic response model MOG2D (Carrère and Lyard 2003). The non-gravitational forces have been corrected using 3-axis accelerometer measurements. In order to reduce the errors in the inter- satellite range rate observations, empirical parameters (bias, bias rate pear revolution, terms of 1-, 2-, 3- and 4- cycle per revolution) have been also adjusted and removed from the KBRR data. The final residuals of KBRR obtained after all corrections should reflect the non modelled geophysical phenomena (post-glacial rebound, earthquakes, models errors and mainly continental hydrology) plus_-model errors and-short-wavelength noise.

\subsection{Datasets used for comparison}

\subsubsection{Mascons solutions}

In this local approach, the mass of water in surface blocks has been explicitly solved using the GRACE inter-satellite KBR Rate (KBRR) data for continental hydrology and collected over the region of interest. The local representation of gravity minimizes the leakage error from other areas due to aliasing or mis-modelling (Rowlands et al., 2005; Lemoine et al., 2007). The mass changes have been solved at 10 -day intervals using $4^{\circ} \times 4^{\circ}$ blocks using temporal and spatial constraints. These "mascons" solutions can be downloaded at: http://grace.sgtinc.com.

\subsubsection{CNES GRGS global solutions}


The Level-2 GRGS-EIGEN-GL04-10day models are derived from Level-1 GRACE measurements including KBRR, and from LAGEOS-1/2 SLR data for enhancement of lower harmonic degrees (Lemoine et al., 2007; Bruinsma et al., 2010). These gravity fields are expressed in terms of normalized spherical harmonic coefficients from degree 2 up to degree 50-60 using an empirical stabilization approach without any smoothing or filtering. 10-day Total Water Storage (TWS) grids of 1-degree spatial resolution are available for 2002-2010 at: http://grgs.obs-mip.fr.

\subsubsection{ICA-filtered solutions}

A post-processing method based on Independent Component Analysis (ICA) was applied to the Level-2 GRACE solutions from different official providers (i.e., UTCSR, JPL, GFZ) prefiltered with $400-\mathrm{km}$ radius Gaussian filters. This approach does not require a priori information, except the assumption of statistical independence between the elementary sources that compose the measured signals (i.e., useful geophysical signals plus noise). Separation consists of solving a linear system relating the GRACE solutions provided for a given month, to the unknown independent sources. The contributors to the observed gravity field are forced to be uncorrelated numerically by imposing diagonal cross-correlation matrices. Time series of ICA-based global maps of continental water mass changes from combined UTCSR, JPL and GFZ GRACE solutions, computed over the period 08/2002 $12 / 2010$, are used in this study. For a given month, the ICA-filtered solutions only differ from a scaling factor, so that the GFZ-derived ICA-filtered solutions are only presented. The efficiency of the ICA in separating gravity signals from noise by combining Level-2 GRACE solutions has previously been demonstrated over land (Frappart et al., 2010, 2011).

An approach based on Independent Component Analysis (ICA) has been applied on the monthly Level-2 RL04 GRACE solutions from CSR, JPL and GFZ, to separate the statistically independent components of the gravity field, i.e., useful geophysical signals from important striping undulations (Frappart et al., 2010, 2011). We use the monthly ICA solutions prefiltered with a $400 \mathrm{~km}$ Gaussian filter, with a $1^{\circ}$ degree spatial resolution and computed for 20032009 .

\subsubsection{WGHM land water storage}

The WaterGAP Global Hydrology Model (WGHM) (Döll et al., 2003; Hunger and Döll, 2008) is a conceptual model that simulates the water balance at a spatial resolution of 0.5 degree-. It represents the continental water cycle using several water storage compartments 
which include interception, soil water, snow, groundwater and surface water (rivers, lakes, wetlands). WGHM has been widely used to analyze spatio-temporal variations of water storage globally and for large river basins (Güntner et al., 2007). In this study, we use 1-by-1 degree daily TWS grids from the latest WGHM version described by Hunger and Döll (2008) for 2002-2007.

\section{Methodology}

\subsection{Differences of potential anomaly from KBRR data}

In a quasi-inertial frame, according to the energy integral method, the Differences of Potential Anomaly (DPA) between GRACE vehicles A and B is related to the KBRR residuals $\dot{\alpha}_{\mathrm{AB}}^{*}$ using the scalar product (see the energy integral method proposed by Ramillien et al., 2011):

$$
\delta \mathrm{V}_{\mathrm{AB}}^{*} \approx \dot{\overline{\mathrm{r}}}_{\mathrm{AB}} \dot{\alpha}_{\mathrm{AB}}^{*}
$$

The upper script symbol "*” is for residuals quantitiesy once the effects of the a priori known accelerations on the KBRR data are removed during the least-squares orbit adjustment for positions and velocities from Level-1 GRACE measurements (see paragraph 1.1). $\dot{\overline{\mathrm{r}}}_{\mathrm{AB}}$ is the arithmetic mean of the velocities of the two GRACE satellites. A similar expression for the determination of the DPA was previously found by Jekeli (1999).

For solving the problem of the important long-wavelength differences between the DPA segments and stabilizinge the inversion, low-degree polynomials are simply removed from the north-southlatitudinal DPA tracks. Obviously, the risk of this operation is to looseeave useful long-wavelength water mass signals which extensions exceed the dimension of the considered region. In the following numerical estimations, we will see that the predicted regional solutions need to be completed by long-wavelength components for comparison with other datasets, when the geographical region is not large enough to contain these wavelengths.

\subsection{The forward problem}

The linear system of equations to be solved is:

$$
\Gamma \mathrm{X}=\mathrm{Y}
$$


where $\mathrm{Y}$ is the vector which contains the $i=1, \ldots N$ observations (i.e., the reduced DPA $\delta \mathrm{V}_{\mathrm{AB}}^{*}$ obtained from KBRR residuals (Eq.1) during the period $\Delta \mathrm{t}$ of survey), and $\mathrm{X}$ is the vector of the $j=1, \ldots M$ parameters (i.e., the equivalent-water heights). $\Gamma$ represents the $\mathrm{N}-b y-\mathrm{M}$ design matrix which elements are derived from a discrete version of the first Newton's law of attraction of masses:

$$
\Gamma_{\mathrm{i}, \mathrm{j}}=\mathrm{G} \rho_{\mathrm{w}} \delta \mathrm{S}_{\mathrm{j}}\left(\frac{1}{\xi_{\mathrm{B}, \mathrm{j}}}-\frac{1}{\xi_{\mathrm{A}, \mathrm{j}}}\right)
$$

where $\mathrm{G}$ is the gravitational constant $\left(\sim 6,67.10^{-11} \mathrm{~m}^{3} \mathrm{~kg}^{-1} \mathrm{~s}^{-2}\right), \rho_{\mathrm{w}}$ is the mean density of water $\left(\sim 1000 \mathrm{~kg} \mathrm{~m}^{-3}\right)$; and $\delta \mathrm{S}_{\mathrm{j}}$ is the elementary surface number j. $\xi_{\mathrm{A}, \mathrm{j}}$ and $\xi_{\mathrm{B}, \mathrm{j}}$ are the Cartesian distances between each GRACE vehicle (A and B) and the centres of the elementary surface tiles. If the inverses of the Cartesian distances in the latter equation are approximated by a discrete sum of Legendre polynomials, the elastic Love numbers $k_{n}$ versus degree harmonic $n$ can be introduced, in order to take the compensation effects of the Earth's surface in response of loading into account (see Eq.24 in Ramillien et al., (2011)).

In the case of a geographical grid, the surface elements are simply given by:

$$
\delta \mathrm{S}_{\mathrm{j}}=\mathrm{R}^{2} \Delta \lambda \Delta \theta \cos \left(\theta_{\mathrm{j}}\right)
$$

where $\mathrm{R}$ is the mean Earth's radius $(\sim 6371 \mathrm{~km}), \Delta \lambda$ and $\Delta \theta$ are the sampling angle intervals along the longitude and the latitude respectively, and $-\theta_{\mathrm{j}}$ is the latitude of the elementary surface element number $\mathrm{j}$.

\subsection{The ill-conditioned inverse problem and its regularization}

The Hadamard's conditions (i.e., existence, continuity and unicity) need to be checked before inversion. The solution of the classical gravity inverse problem usually exists and is continuous, but also is not unique. By computing the SVD of $\Gamma$, the rank of the operator (i.e., the number of non-zero singular values) - and thus the dimension of its kernel - can be easily determined. For example, the set of singular values in the case of differences of potential anomalies over South America for August 2009, simultaneously contains very small and large quantities. Consequently, the generalized condition number of the system is large. In practice, the Newtonian operator is simply constructed with Cartesian distances $\xi_{\mathrm{A}, \mathrm{B}}$ that are very close numerically, and thus they produce nearly identical lines and columns in the matrix $\Gamma$. 
1 2

$$
\varepsilon^{2}=\|\mathrm{Y}-\Gamma \mathrm{X}\|^{2}+\alpha\|\mathrm{CX}\|^{2}
$$

where an extra squared term is added to the classical least-squares term $\|\mathrm{Y}-\Gamma \mathrm{X}\|^{2}$ to stabilize the linear system to solve. $\alpha$ is here the regularization parameter that counterbalances the weights of the model with the constraints from the M-by-M element matrix C. As the solution $\hat{\mathrm{X}}$ corresponds to the minimum of the Eq.6, By differentiating this latter expression is differentiated versus each componentelement of the vector $\mathrm{X}_{2}$ and_setting these new equations are setthem to zero.; This set of conditions of extremum yields the regularized least-squares solution: the conditions for extreme values are obtained, and then the numerical solution of this set of conditions is given by:

$$
\hat{\mathrm{X}}=\left(\Gamma^{\mathrm{T}} \Gamma+\alpha \mathrm{C}^{\mathrm{T}} \mathrm{C}\right)^{-1} \Gamma^{\mathrm{T}} \mathrm{Y}
$$

Note that the unstable least-squares solution is easily found when $\alpha=0$.

The difficulty is to keep a numerical compensation between the normal matrices $\Gamma^{\mathrm{T}} \Gamma$ and $\mathrm{C}^{\mathrm{T}} \mathrm{C}$. In practice, the regularization parameter $\alpha$ can be chosen as the square-root of the squared elements of the normal matrix $\Gamma^{\mathrm{T}} \Gamma$ (see Dimri, 1992, p.145). In our case of inversion of GRACE-derived DPAdifferences of potential,_weregularization parametersevaluated for each 10-day period, and numerical values ranging from $1.83 \times 10^{-4}$ to $1.15 \times 10^{-3}$ are found following this simple expression.

have the condition

\subsection{Definition of the spatial constraints}

Let $\mathrm{B}$ be the M-by-M elements matrix containing the spatial constraints with diagonal entries equal to zero such as:

$$
\mathrm{X}=\mathrm{BX}
$$

In other words, each value of $\mathrm{X}$ is simply a linear combination of the other values of the solution itself. We have equivalently:

$$
\mathrm{CX}=0
$$

with:

$$
\mathrm{C}=\mathrm{Id}-\mathrm{B}
$$


1 where Id denotes the identity matrix, so that $\mathrm{C}$ has a dominant diagonal.

2 Let $\varphi_{\mathrm{i}, \mathrm{j}}$ be the spherical distance between the surface elements numbers $\mathrm{i}$ and $\mathrm{j}$, and $\varphi_{0}$ the 3 maximum radius of the correlation. $\mathrm{L}\left(\varphi_{0}\right)$ is the number of surface tiles inside the 4 geographical disk of radius $\varphi_{0}$ and of which the surface element number $\mathrm{i}$ is the center.

5 Different correlations versus spherical distance can be defined for $\varphi_{\mathrm{i}, \mathrm{j}} \leq \varphi_{0}$ :

6 - Case 1: Uniform weighting (MOY):

$7 \quad \mathrm{~B}_{\mathrm{i}, \mathrm{j}}=1 / \mathrm{L}\left(\varphi_{0}\right)$

8 - Case 2: Linear weighting (LIN):

9

$$
\mathrm{B}_{\mathrm{i}, \mathrm{j}}=\left(1-\left|\frac{\varphi_{\mathrm{i}, \mathrm{j}}}{\varphi_{0}}\right|\right) / \mathrm{L}\left(\varphi_{0}\right)
$$

10 - Case 3: Exponential-type weighting (EXP):

$$
\mathrm{B}_{\mathrm{i}, \mathrm{j}}=\exp \left(-\left|\varphi_{\mathrm{i}, \mathrm{j}} / \chi\right|\right) / \mathrm{L}\left(\varphi_{0}\right) \text { with } \chi=\frac{\lambda}{2 \ln 2}
$$

- Case 4: Gaussian-type weighting (GAU):

$$
\mathrm{B}_{\mathrm{i}, \mathrm{j}}=\exp \left(-\left(\varphi_{\mathrm{i}, \mathrm{j}} / \chi\right)^{2}\right) / \mathrm{L}\left(\varphi_{0}\right) \text { with } \chi=\frac{\lambda}{2 \sqrt{\ln 2}}
$$

And in these fourthree cases, $\mathrm{B}_{\mathrm{i}, \mathrm{j}}=0$ if $\varphi_{\mathrm{i}, \mathrm{j}}>\varphi_{0}$. The extra term $\chi$ is a spatial "damping" factor that depends upon the length of correlation $\lambda$, such as $\mathrm{B}_{\mathrm{i}, \mathrm{j}}=\frac{1}{4 \mathrm{~L}\left(\varphi_{0}\right)}$ and $\mathrm{B}_{\mathrm{i}, \mathrm{j}}=\frac{1}{16 \mathrm{~L}\left(\varphi_{0}\right)}$ if $\varphi_{\mathrm{i}, \mathrm{j}}=\lambda$ (i.e., the half height at a chosen correlation length) for eitherthe cases numbers 3 or caseand 4, respectively. By construction, the matrix B is symmetric (i.e., $B_{i j}=B_{j i}$ for any pair of integers $i$ and $j$ ), and its diagonal entries are zeros.

\section{Numerical applications}

\subsection{Preliminary tests}

Level-1 GRACE data are used to adjust daily orbits with known a priori accelerations as explained in paragraph 1.1. Residual KBRR data are used to compute trend-corrected DPA tracks passing over the selected area (e.g., South America $\left.\left[60^{\circ} \mathrm{S}-20^{\circ} \mathrm{N} ; 90^{\circ} \mathrm{W}-30^{\circ} \mathrm{W}\right]\right)$ for 1 10 AugustSeptember, 2009, after having implemented the modified least-squares estimator 
(Eq.7). A regional solution is inverted from 10-day DPA for a given set of correlation radius $\lambda$ and size of elementary tiles. Note that the case of $\lambda=0$ corresponds to a determination of spatially uncorrelated water heights, and leadsyields to a noisy solution with unrealistic shortwavelength amplitudes. Figure 1 presents 10-day regional solutions considering surface elements of decreasing sizes $\Delta \theta$ (i.e., or $\Delta \lambda$ ), revealing the estimated amplitudes remain roughly the same for surface mass elements from 1 to 4 degrees. Figure 2 shows the loss of spatial resolution due to the smoothing when considering increasing exponential-type correlation radii. Errors of recovery versus combination of $\alpha \lambda_{2}-$ and $\_\Delta \lambda \Delta \theta \underline{\text { and }}$ $\Delta \theta$ parameters are determined using simulated hydrology-based DPA tracks over South America from the WGHM global hydrology model (Döll et al., 2003; Hunger and Döll, 2008) by using simply the Newtonian operator $\Gamma$ associated with the whole region, and these errors are plotted on Figure_3. Errors of recovery_i.e., differences between reference model values and regularized least-square estimates from Eq.7) areis largergenerally more important for Gaussian-type (i.e., GAU) weighting (Eq.11d) than for exponential-type (i.e., EXP) and linear/uniform-type weightings (i.e., LIN and MOY resp.) (Eq.11a-b-c). $\underline{S}$ They suggest that the smoothing with a correlation radius reduces the long-wavelength error, but surely still removesmiss the short-wavelength details. When white noise generated with various numerical seeds isare input into the simulated DPA data, spatial correlations enable to attenuate efficiently the effect of this polluting noise in the recovery (Figure 4), the reduction of error amplitude represents at least $50 \%$ when $\lambda>600 \mathrm{~km}$ for a realistic noise level of $10^{-3}$ $\mathrm{m}^{2} / \mathrm{s}^{2}$, and then almost unchanged after $800 \mathrm{~km}$.

\subsection{Computation of regional solution time series for South America}

Small surface elements ( $\sim 1$ degree) could be estimated to improve the level of details in our solutions. However, as mentioned previously by Ramillien et al. (2011), the intrinsic optimal spatial resolution of the GRACE data remains limited at $\sim 200-300 \mathrm{~km}$, so that considering 2degree tiles computation is enough to catch all the GRACE resolution. As illustrated on Fig.1, there is no change of amplitude by decreasing the size of the tiles and no gain of details. Four years (2006-2009) of KBRR residuals for continental hydrology were used to estimate regional mass changes by solving daily normal equations $\Gamma^{T} \Gamma$ obtained from residual DPA using Eq.7 and considering an exponential-type weighting. Dealing with factorization of symmetric normal equations remains faster than using a SVD decomposition of normal equations before L-curve regularization (Ramillien et al., 2011). 
1 As shown by testing different input parameters (Figures 2 and 4), a correlation radius of 600

$2 \mathrm{~km}$ for continental hydrology is a good compromise between reduction of noise and 3 smoothness. In order to damp unrealistic oscillations over oceans, a longer radius of 4 thousands of $\mathrm{km}$ can be used. By using a geographical mask, we can distinguish different 5 spatial constraints over continents and oceans (i.e., 600 and $5000 \mathrm{~km}_{2}$ respectively). The 6 corresponding 2-degree constrained regional solutions are presented on Figure 5a and Figure 7 5b for the whole-recent year 2009, and they reveal a complete seasonal water cycle for South 8 America. Estimated equivalent-water heights over the continent are detailed and in the annual 9 range of $+/-300 \mathrm{~mm}$ locally. As expected, regional solutions exhibit important seasonalasonal 10 amplitudes, especially over the large drainage basins of the Amazon, Orinoco, Tocantins, and 11 Parana rivers. A persistent mass depletion is also observed for the coastal Patagonian glaciers.

12 However, strong spatial constraints have efficiently damped the long-wavelength DPA signals over the oceanic areas. The remaining signals over the ocean are probably due to aliasing 14 versus time and errors in correcting models. Loss of energy from continental hydrology signals cannot be excluded as well. Besides, short-term water mass events can be easily seen on these regional maps, corresponding to large floods occurring over the north east of the Amazon basin in June 2009 and over the Parana in November 2009, as seen in (Figure 5b).

\section{Discussion}

Introducing spatial correlations between surface elements enables us to stabilize numerically the inversion and to cancel the effects of the longitudinallatitudinal striping. This method eliminates the unrealistic signals errors in de-aliasing models over the oceans, when a geographical mask is used.

The regional approach proposed here suppresses drawbacks of striping error inherent to measurement configuration and temporal aliasinga, as global spectral representation because:

(i) the reduction of thene north-south striping in the solution as using constrained regularization with a geographical radius remains more flexible with space localizing representation, no spherical harmonics coefficient is fitted and satellite tracks are corrected of long-term trend, and (ii) by construction there is no contamination of signals from other parts of the world.

2 and 4-degree solutions provide very comparable averages versus time, this remains consistent with the previous test on the impact of choosing different sizes for surface tiles in the inversion (see results of Figure 1). 
For validation, our regional estimates of change in continental water storage are confronted to time series from other GRACE-based products ("mascons", GRGS, ICA) and WGHM global hydrology model outputs. We consider local (i.e., at the size of a surface tile) and averaged water mass signals versus time over the Amazon basin, as it is the biggest drainage basin of the world ( $\sim 6$ millions of square kilometres), and where redistributions of large amounts of surface waters occur.

Regional solutions for March and September 2006 are confronted to other GRACE-based solutions (i.e., (a) "stabilized" 10-day and 4-degree global solutions from GRGS, (b) 10-day and 4-degree NASA "mascons" and (c) monthly and 4-degree ICA global solutions) in Figure 6. For comparison purposes, the 10-day solutions were averaged over a month to be consistent with the global monthly solutions. They show similar structures of water mass anomaly, especially in the southern part of the Amazon basin. However, the amplitudes of the regional solutions are largermere impertant (up to +/-395 $\mathrm{mm}$ and +/-450 $\mathrm{mm}$ of equivalentwater height for March and September, respectively) and appear to contain more details. Once the one-degree global grids are interpolated into 2-degree tiles, the spatial correlations with these other datasets for March 2006 are high: 87\% and 83\% for (a) and (c) respectively. Six months later they are of $87 \%$ and $88 \%$. 4-degree solutions have been also computed to be compared at the same spatial resolution to the available "mascons" solutions, and they present water mass structures of comparable water mass amplitudes. For the same periods and at the scale of the whole South America continent, power spectrum analysis reveal that the regional solutions are more energetic than the band-limited global solutions (GRGS, ICA, "mascons") at short and medium spatial wavelengths $(<4000 \mathrm{~km}$ ) (Figure 7). Regional solutions logically contain more energy at very short wavelengths (by a factor 10 of the other power spectra) near the Nyquist frequency $(\sim 400 \mathrm{~km})$, as the spatial sampling (i.e., the size of the surface tiles) is better $(\sim 200 \mathrm{~km})$.

The seasonal variations of the water mass averaged in the large Amazon basin are clearly sinusoidal with a positive maximum in April-May (Figure 8). As previously suspected by Rowlands et al. (2010), once averaged over a large region, 4-degree "mascons" estimates are comparable to global approaches that are also based on spherical harmonics. Both global and "mascons" solutions present seasonal amplitudes reaching $+/-180 \mathrm{~mm}$ of equivalent-water thickness. As presented on Figure 9, the differences of amplitudes between the spherical harmonics and constrained regional solutions for 2006 are clearly seasonal with peak-to-peak amplitudes of $+/-90 \mathrm{~mm}$ of equivalent-water height. These latter differences are completely explained by the loss of very long wavelengths (or equivalently, lower harmonic degrees of 
1 the observed gravity signals) due to the de-trending of the DPA tracks made over South

2 America before regional inversion, as explained at the end of paragraph 2.1. Latitudinal

3 extend of the studied region being of $80^{\circ}$ (i.e., distance of $\mathrm{d} \sim 8000 \mathrm{~km}$ ), the cut-off degree of

4 the signals lost by linear de-trending should be $\sim \frac{2 \pi R}{d}$, thus numerically $n \sim 5$. The

numerical verification is presented on Figure 9, where the best agreement between 2-degree regional and global 10-day solutions and long-wavelength gravity signals from GRGS is found for harmonic degree 5, with a Root Mean Square (RMS) difference of only $11 \mathrm{~mm}$ of equivalent-water height. Once this bias is corrected in the Total Water Storage (TWS) time series, global and regional techniques both yield to comparable spatial averages.

Another way to for avoiding to loosinge long-wavelengths in the inversion is to increase the latitudinal extension in latitude of the considered area, as presented Figure 10, where the "stabilized" GRACE GRGS solution for the first 10 days of March 2009 is compared to the smooth regional solution computed on nearly a third of the Earth's surface. The localisations and amplitudes of water mass anomalies on continents are comparable, howeverbut the GRGS solution contains nNNorth-s South striping. Consequently, the differences between the two solutions correspond to these spurious undulations due to aliasing effects in the spherical harmonics (Figure 10c).

Manaus $\left(3^{\circ} \mathrm{S}-60^{\circ} \mathrm{W}\right)$ is located roughly at the center of the Amazon basin, at the mouth of the Negro River, slightly upstream the convergence of the two major rivers forming the Amazon River: Solimoes and Rio Negro tributaries. Local time series are simply interpolated from gridded values or from surface tiles centered on Manaus, they are presented on Figure 11. All the Manaus time series show that the main seasonal variation for 2006 are very consistent to each others, in particular the slow increase of water mass until the middle of June and up to 400-500 mm of equivalent-water height, and the rapid decrease afterwards. However, the 4degree "mascons" signal at Manaus hasve less amplitudes (reaching only $\sim 350 \mathrm{~mm}$ in Spring), and is smoother than the other profiles. This smoothing is probably due to the damping effects of correlations of 10-30 days and the 4-degree averaging used in the processing of "mascons" solutions (Luthcke et al, 2006; Lemoine et al., 2007). The WGHMderived TWS time series shows important intra-annual variability during the first six months of the year, which is corresponds to important rainfall events that occurred in October/November 2005, causing floods in January/February 2006, especially in the Rio Negro basin (Marengo et al., 2008). The signature of this unusual flood can be noticed by the presence of a peak of water level in the gauge records, as for instance, at the Observatoire 
Régionale de l'Environnement (ORE) Hybam (http://www.ore-hybam.org/) station of 2 Serrinha $\left(0.48^{\circ} \mathrm{S}-64.82^{\circ} \mathrm{W}\right)$.

3

\section{CONCLUSION}

We proposed a new regional least-squares approach to estimate surface water mass variations from GRACE-based KBRR residuals for continental hydrology. Spatial constraints have been added to stabilize the ill-conditioned linear system of equations to solve, as well as for attenuating the effects of the noise. In particular, there is no difference in predicted water mass amplitudes considering grid samplings of 1, 2 and 4 degrees, suggesting the final spatial resolution of the regional grids is limited by the intrinsic resolution of the GRACE data $(\sim 200-300 \mathrm{~km})$ available for the chosen period. Different types of spatial constraints have been implemented, and they provided similar amplitudes once the smoothing radius is fixed. It is clear that a compromise between averaging radius and the final spatial resolution has to be found. Inversion of simulated error-free potential differences provided formal uncertainties of $\sim 3-4 \mathrm{~cm}$ of equivalent-water height for smoothing radii from 200 to $2500 \mathrm{~km}$. Random large-band noise of $10^{-2} \mathrm{~m}^{2} / \mathrm{s}^{2}$ magnitude produces errors of 1-2 $\mathrm{cm}$ of equivalent-water height. Time series of successive 10-day regional maps of water mass over South America have been successfully computed for several years, so that short-term hydrological variations have been detected, such as sudden inundation events. Regional maps are consistent with other independent datasets, however they are more detailed. The promising regional inversion of GRACE KBRR data will be extended to the full multi-year period of GRACE observations. Obviously, constrained regional solutions can be easily estimated_easily_in other continental areas, such as Africa, Europe, North America and Australia, and they offer interesting applications in the detection of continental water mass changes.

\section{Acknowledgments}

Dr. Lucia Seoane's work was funded by the ADTAO project of RTRA/STAE on numerical methods of regularization. We would like to thank an anonymous reviewer for his fruitful comments on the manuscript.

\section{References}


Carrère L. and F. Lyard, 2003, Modeling the barotropic response of the global ocean to atmospheric wind and pressure forcing - comparisons with observations. Geophys. Res. Lett. 30, 1275, doi:10.1029/2002GL016473.

Chambers D. P., J. Wahr, and R. S. Nerem, 2004, Preliminary observations of global ocean mass variations with GRACE, Geophys. Res. Lett., 31, L13310, doi:10.1029/2004GL020461.

Chen J. L., B. D. Tapley and C. R. Wilson, 2006, Alaskian mountain glacial melting observed by satellite gravimetry, 248, 1-2, 368-378, doi: 10.1016/j.eps1.2006.05.039.

Davis J. L., P. Elósegui, J. X. Mitrovica, and M. E. Tamisiea, 2004, Climate-driven deformation of the solid Earth from GRACE and GPS, Geophys. Res. Lett., 31, L24605, doi:10.1029/2004GL021435.

Desai S., 2002, Observing the pole tide with satellite altimetry, J. Geophys. Res., vol. 107 3186, 107, doi: 10.1029/2001JC001224.:

Dimri V., 1992, Deconvolution and inverse theory: Application to geophysical problems, Methods in Geochemistry and Geophysics, Elsevier, Amsterdam-London-New York-Tokyo, 230 pp., ISBN: 0-444-89493-4.

Döll P., F. Kaspar and B. Lehner, 2003, A global hydrological model for deriving water availability indicators: model tuning and validation, Journal of Hydrology, 270(1-2), 105-134.

Frappart, F., G. Ramillien, P. Maisongrande and M.-P. Bonnet, 2010, Denoising satellite gravity signals by Independent Component Analysis. IEEE Geosciences and Remote Sensing Letters, 7(3), 421-425, doi:10.1109/LGRS.2009.2037837.

Frappart F., G. Ramillien, M. Leblanc, S. O. Tweed, M.-P. Bonnet and P. Maisongrande, 2011, An independent Component Analysis approach for filtering continental hydrology in the GRACE gravity data, Remote Sensing of Environment, 115, 1, doi: 10.1016/j.rse.2010.08.017. 
Garcia R. V., 2002, Local geoid determination from GRACE mission, report 43210-1275, Ohio State University, Columbus.

Güntner A., J. Stuck, S. Werth, P. Döll, K. Verzano and B. Merz, 2007, A global analysis of temporal and spatial variations in continental water storage, Water Resources Research, 43, W05416.

Han S.-C., C. Jekeli, C. K. Shum, 2003, Static and temporal gravity field recovery using GRACE potential difference observables, Adv. Geosci, 1, 19-26.

Han S.-C., 2004, Efficient determination of global gravity field from satellite-to-satellite tracking mission GRACE, Celest. Mech. Dyn. Astron., 88, 69-102.

Han S.-C., C. K. Shum, J. Jekeli and D. Alsdorf, 2005, Improved estimation of terrestrial water storage changes from GRACE, GRL, 32, L07302, doi: 10.1029/2005GL02238.

Hunger M. and P. Döll, 2007, Value of river discharge data for global-scale hydrological modeling, Hydrology and Earth System Sciences, 12, 3, 841-861.

IERS Conventions, 2003, McCarthy D. and Petit G., eds, IERS Technical Note 32.

Jekeli C., 1999, The determination of gravitational potential differences from satellite-tosatellite tracking, Celest. Mech. Dyn. Astron., 7582, 85-101.

Kusche J., 2007, Approximate decorrelation and non-isotropic smoothing of time-variable GRACE-type gravity fields, J. of Geodesy, 81, 11, 733-749, doi: 10.1007/s00190-007-01433.

Lemoine J.-M., S. Bruinsma, S. Loyer, R. Biancale, J.-C. Marty, F. Pérosanz, and G. Balmino, "Temporal gravity field models inferred from GRACE data," Adv. Space Res., vol. 39, no. 10, pp. 1620-1629, Oct. 2007. 
Lemoine, F. G., et al., 1998, The Development of the Joint NASA GSFC and the National Imagery and Mapping Agency (NIMA) Geopotential Model EGM96, NASA/TP-1998206861, July 1998.

Lemoine, F. G., Luthcke, S. B., Rowlands, D. D., Chinn, D. S., Klosko, S. M., Cox, C. M., (2007). The use of mascons to resolve time-variable gravity from GRACE Dynamic Planet: Monitoring and Understanding A Dynamic Planet with Geodetic and Oceanographic Tools, Vol. 130: pp. 231-236, 2007. Book Series: INTERNATIONAL ASSOCIATION OF GEODESY SYMPOSIA Editor(s): Tregoning P. \& Rizos C., Conference Information: IAG Symposium on Dynamic Planet Cairns, AUSTRALIA, AUG 22-26, 2005.

LeProvost C., Genco M., Lyard F., Vincent P. and P. Canceil P., 1994, Spectroscopy of the world ocean tides from a finite element hydrodynamic model, J. Geophys. Res., 99, C12, 24777-24797, Special TOPEX/POSEIDON issue.

Luthcke S. B., H. J. Zwally, W. Abdalati, D. D. Rowlands, R. D. Ray, R. S. Nerem, F. G. Lemoine, J. J. McCarthy and D. S. Chinn, 2006, Recent Greenland ice mass loss by drainage system from satellite gravity observations, Science, 314 (5803), 1286-1289, doi: 10.1126/science. 1130776 .

Luthcke, S. B., A. A. Arendt, D. D. Rowlands, J. J. McCarthy and C.F. Larsen, 2008, Recent glacier mass changes in the Gulf of Alaska region from GRACE mascon solutions $s_{2}+$ Journal of Glaciologyt, Vol. 54, No. 188.

Marengo J. A., C. A. Noble, J. Tomasella, M. Oyama, G. Sampaio, H. Camargo and L. M. Alves, 2008, The drought in Amazonia in 2005, J. of Climate, 21, 495-516.

Ramillien G., F. Frappart, A. Cazenave and A. Güntner, 2005, Time variations of land water storage from an inversion of GRACE geoids, EPSL, 235, 1-2, 283-301, doi: 10.1016/j.eps1.2005.04.005.

Ramillien G., J. Famiglietti and J. Wahr, 2008, Detection of continental hydrology and glaciology signals from GRACE: a review, Surveys in Geophysics, Special issue: Hydrology from Space, doi: 10.1007/s10712-008-9048-9. 
Ramillien G., R. Biancale, S. Gratton, X. Vasseur and S. Bourgogne, 2011, GRACE-derived surface mass anomalies by energy integral approach. Application to continental hydrology, J. of Geodesy, 85, 6, 313-328, doi: 10.1007/s00190-010-0438-7.

Rowlands D. D., R. D. Ray, D. S. Chinn and F. G. Lemoine, 2002, Short-arc analysis of intersatellite tracking data in a mapping mission, J. of Geodesy, 76, 307-316, doi: 10.1007/s.00190-002-0255-8.

Rowlands D. D., S. B. Luthcke, S. M. Klosko, F. G. R. Lemoine, D. S. Chinn, J. J. McCarthy, C. M. Cox, O. B. Anderson, 2005, Resolving mass flux at high spatial and temporal resolution using GRACE intersatellite measurements, Geophys. Res. Lett., 32, L04310, doi:10.1029/2004GL021908.

Rowlands D. D., S. B. Luthcke, J. J. McCarthy, S. M. Klosko, D. S. Chinn, F. G. Lemoine, J.P. Boy and T. J. Sabaka, 2010, Global mass flux solutions from GRACE: a comparison of parameter estimation strategies - Mass concentrations versus Stokes coefficients, J. of Geophys. Res., 115, B01403, doi: 10.1029/2009JB006546.

Schmidt R., P. Schwintzer, F. Flechtner, C. Reigber, A. Güntner, P. Döll, G. Ramillien, A. Cazenave, S. Petrovic, H. Jochmann and J. Wunsch, 2006, GRACE observations of changes in continental water storage, Global Planetary Change, 50 (1-2), 112-126, doi: 10.1016/j.gloplacha.2004.11.018.

Standish E. M., Newhall X.X, Williams J.G. et al., 1995, JPL Planetary and Lunar Ephemerids, DE403/LE403, JPL IOM 314.10-127.

Swenson S. and J. Wahr, 2006, Estimating large scale precipitation minus evapotranspiration from GRACE satellite gravimetry measurements, J. Meteorol., 7 (2), 252-270, doi: 10.1175/JHM478.1.

Tapley B., S. Bettadpur, M. Watkins and C. Reigber, 2004a, The gravity recovery and climate experiment: mission overview and early results, GRL, 31, L09607, doi: 10.1029/2004GL019920.

Tapley B., S. Bettadpur, J. Ries, P. Thompson and M. Watkins, 2004b, GRACE 
1 measurements of mass variability in the Earth system, Science, 305 (5683), 503-505, doi:

$2 \quad 10.1126 /$ science.1099192.

3 Velicogna I. and J. Wahr, 2006, Measurements of time-variable gravity show mass loss in

4 Antarctica, Science, 311, 1754-1756.

Wagner C. D., D. McAdoo, J. Klokocnic and J. Kostelecky, 2006, Degradation of geopotential recovery from short repeat-cycle orbits: Application to GRACE monthly fields, J. of Geodesy, 80, 94-103, doi: 10.1007/s00190-006-0036-x.

Wahr J., F. Molenaar and F. Bryan, 1998, Time variability of the Earth's gravity field: hydrological and oceanic effects and their possible detection using GRACE, J. Geophys. Res., 103 (B12), 30,205-30,229.

Zlotnicki V., J. Wahr, I. Fukumori and Y. Song, 2007, Antarctic circum-polar current transport variability during 2003-05 from GRACE, J. Phys. Oceanogr., 37, 230-244. 
3 Figure 1: 4-degree (a), 2-degree (b), and 1-degree "constrained" regional solutions over 4 South America computed with KBRR residuals of 1-10 August, 2006, and for different grid samplings. The correlation radius is $600 \mathrm{~km}$ for the three cases. They reveal roughly similar amplitudes of water mass anomaly.

Figure 2: 1-degree regional solutions computed with different lengths of correlation: (a) 200 km, (b) $400 \mathrm{~km}$, (c) $600 \mathrm{~km}$ and (d) $800 \mathrm{~km}$. Note the important smoothing (i.e., loss of shortwavelength details) as the correlation radius increases.

Figure 3: Decrease of the recovery error versus the correlation radius for a simulated case of GRACE tracks over South America. Star, triangle and circle symbols are for MOY, EXP and GAU types of geographical correlation respectively (see Eq.11 a-d). Grey curves are for the 1-degree grid inversion, whereas black and dotted curves are for 2 and 4-degree grids respectively.

Figure 4: Errors of recovery from noisy potential anomaly data. Noise is generated randomly using different seeds and added before inversion. Smoothing clearly attenuates the effects of the noise.

Figure 5a and 5b: Time series of 2-degree regional solutions over South America from January to December, 2009. The correlation radii are $600 \mathrm{~km}$ and $5000 \mathrm{~km}$ over the continents and oceans, respectively.

Figure 6: Six-month interval water mass solutions derived from GRACE data (from top to bottom): 2-degree constrained regional solutions; 4-degree NASA "mascons" solutions; ICAfiltered solutions (Frappart et al., 2011); 10-day GRGS global solutions (Lemoine et al., 1997). First and the second columns are for March and September, 2006, respectively.

Figure 7: Radial power spectrum of water mass variations over South America for (a) March 2006 and (b) September 2006: 2-degree regional solutions (solid lines), 10-day GRGS global solutions (dashed lines) and 400-km ICA global solutions (grey lines). 
1 Figure 8: GRACE-based products and WGHM global hydrology model averaged on the 2 Amazon River basin for the year 2006. Symbols: crosses: 10-day GRGS solutions; circles: 3 400-km ICA solutions; dashed line: 4-deg. "mascons" from NASA; solid line: daily WGHM 4 outputs; and black and white stars: 2 and 4-deg. regional solutions, respectively.

Figure 9: Time series of the differences between 10-day GRGS global solutions and 2degree constrained regional solutions for 2006 (solid line). Spherical harmonics from GRGS averaged over the Amazon basin for maximum degrees: $n=4$ (black circles), $n=5$ (black stars) and $\mathrm{n}=6$ (white circles). A minimum value of root mean square differences of $\sim 11 \mathrm{~mm}$ of equivalent-water height is found for $n=5$.

Figure 10: (a) "stabilizsed" 10-day GRGS solution and (b) regional solution computed over the same large area $\left[60^{\circ} \mathrm{S}-70^{\circ} \mathrm{N} ; 180^{\circ} \mathrm{W}-30^{\circ} \mathrm{W}\right]$ of the two Americas, for the beginning of March 2009. The map of difference (a) minus (b) reveals the important North-South striping on the continents (c).

Figure 11: Time series of equivalent-water height at Manaus station for 2006 according to the datasets presented on Fig.6. Symbols are the same as for Fig.8. 
Figure 1

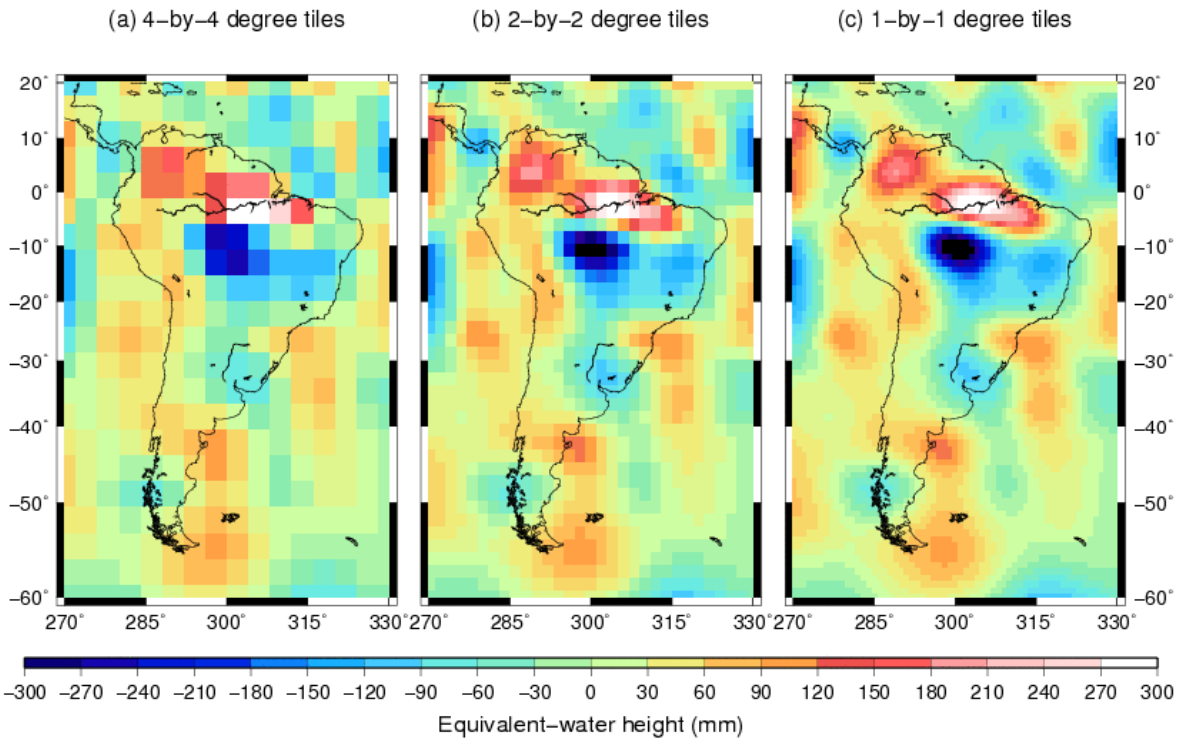


Figure 2

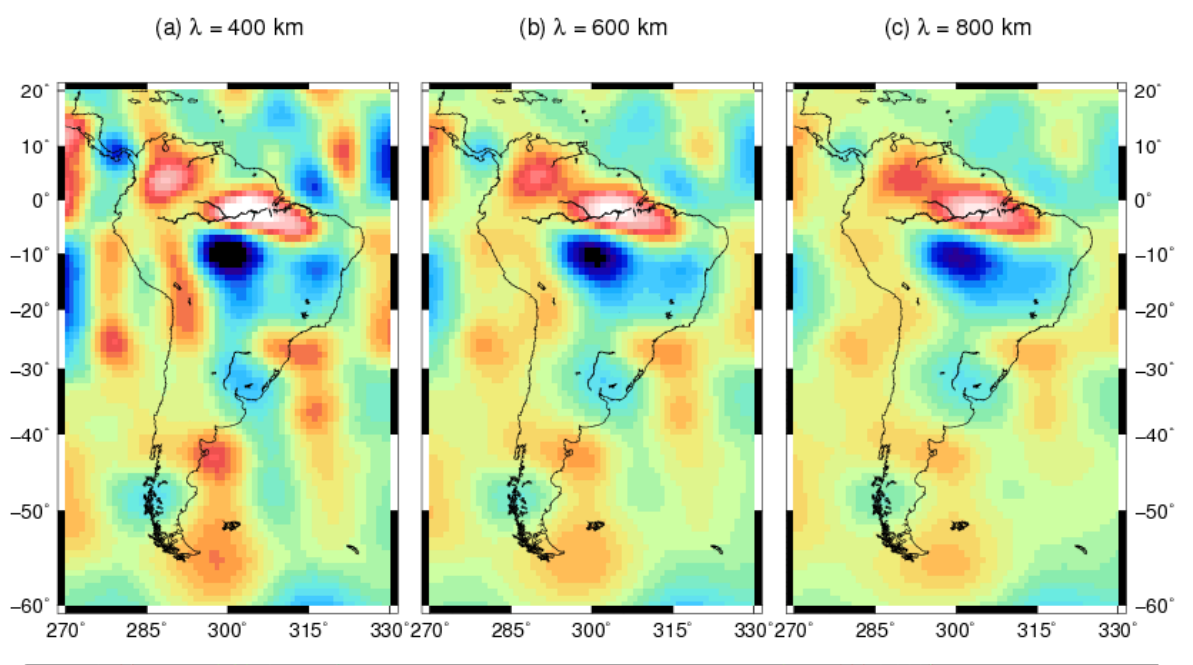

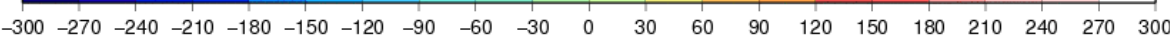
Equivalent-water height $(\mathrm{mm})$ 
Figure 3

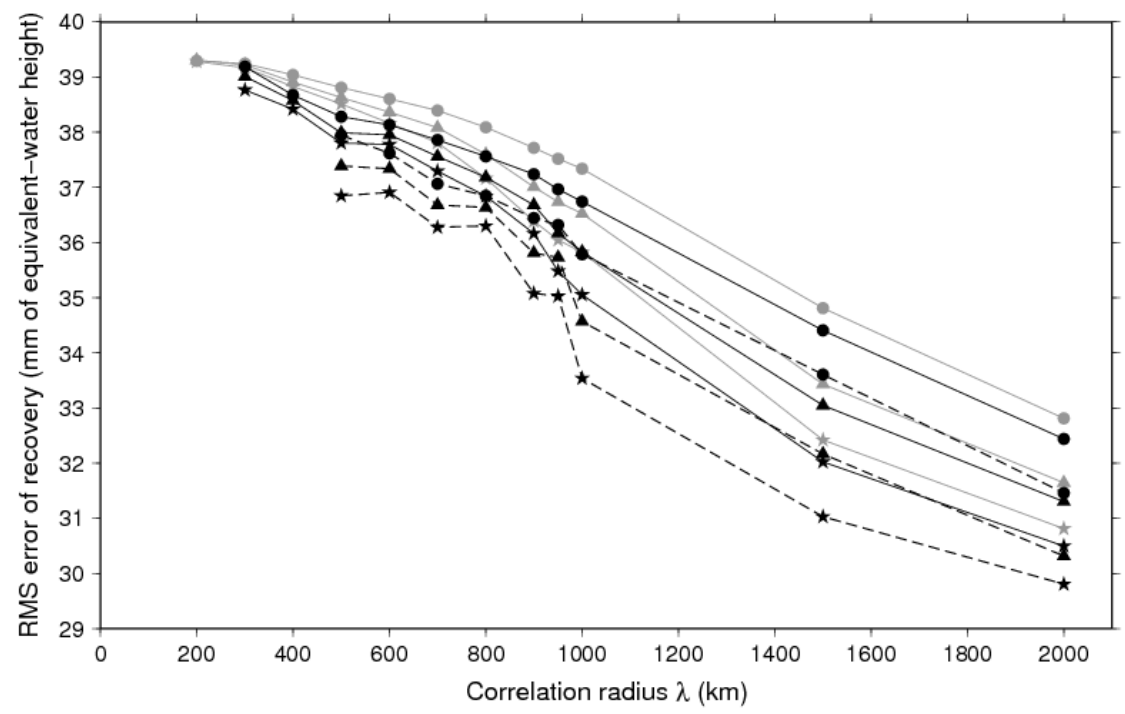

3

4

5

6 
Figure 4

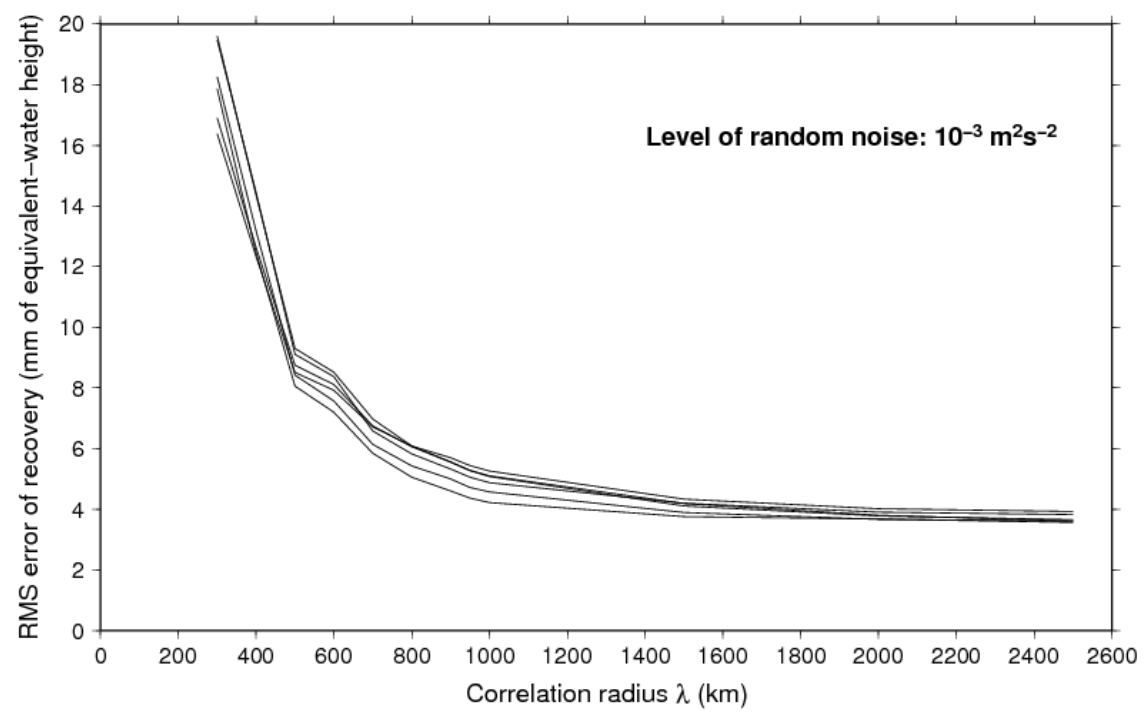

3 


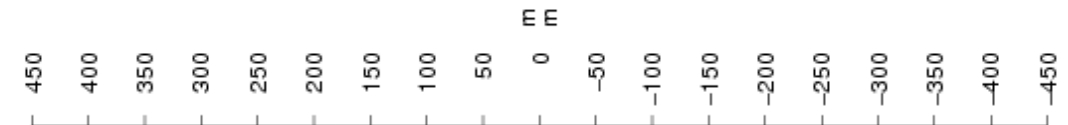

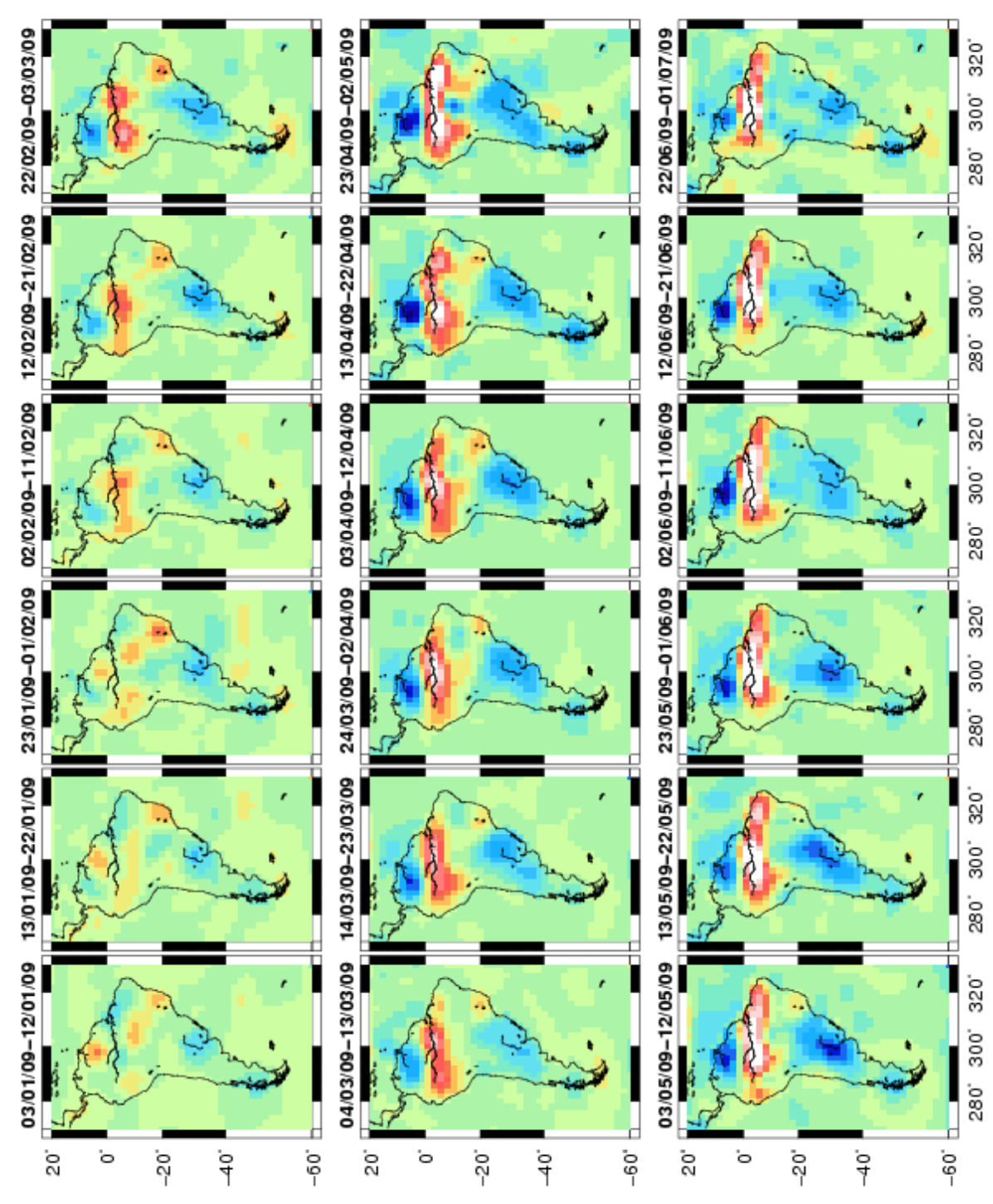




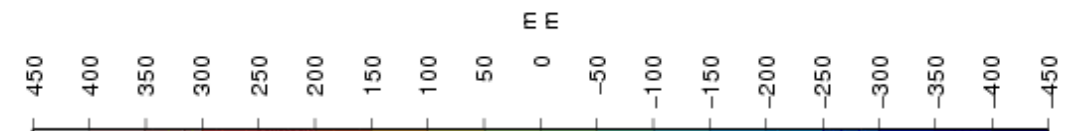

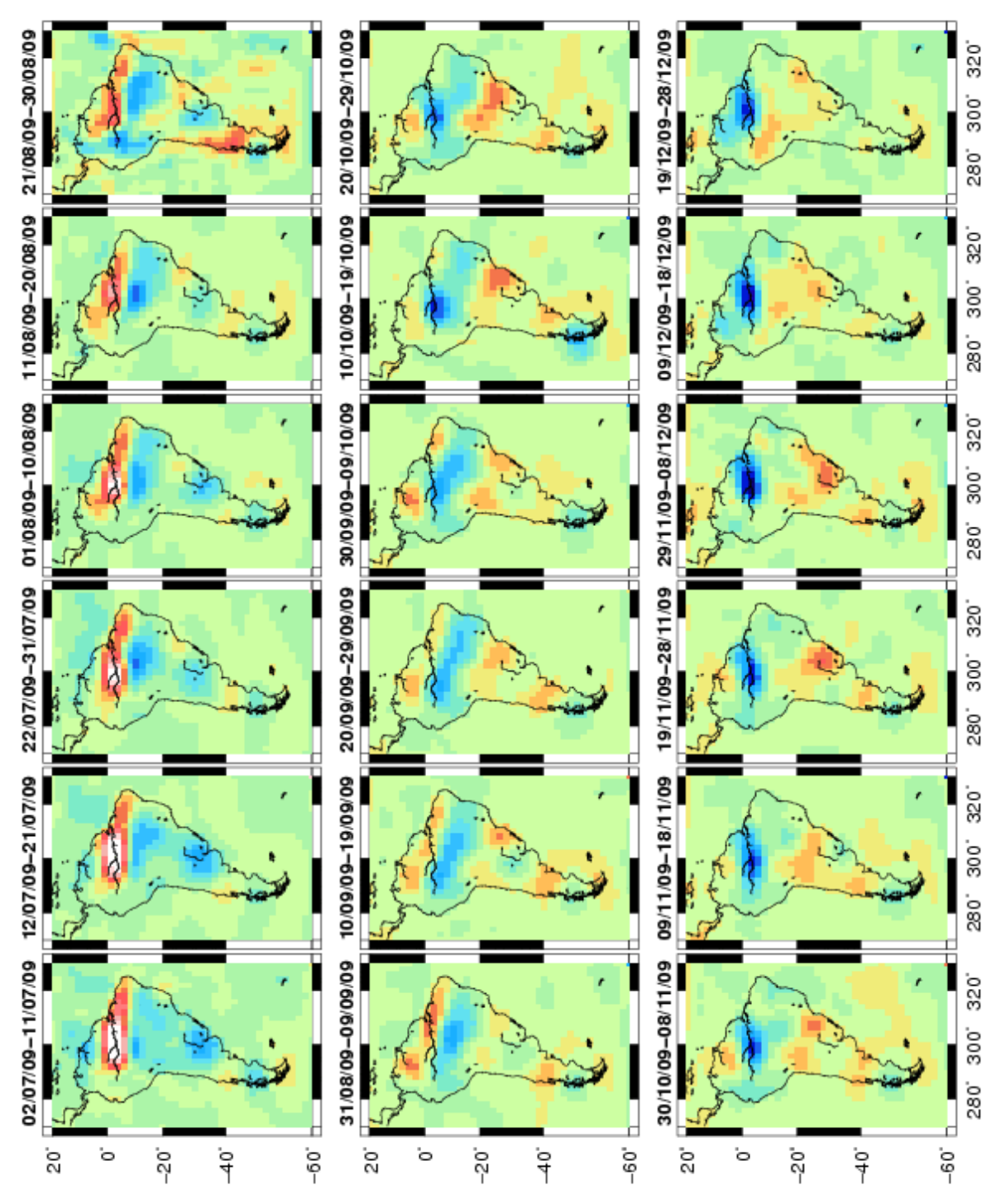


Figure 6
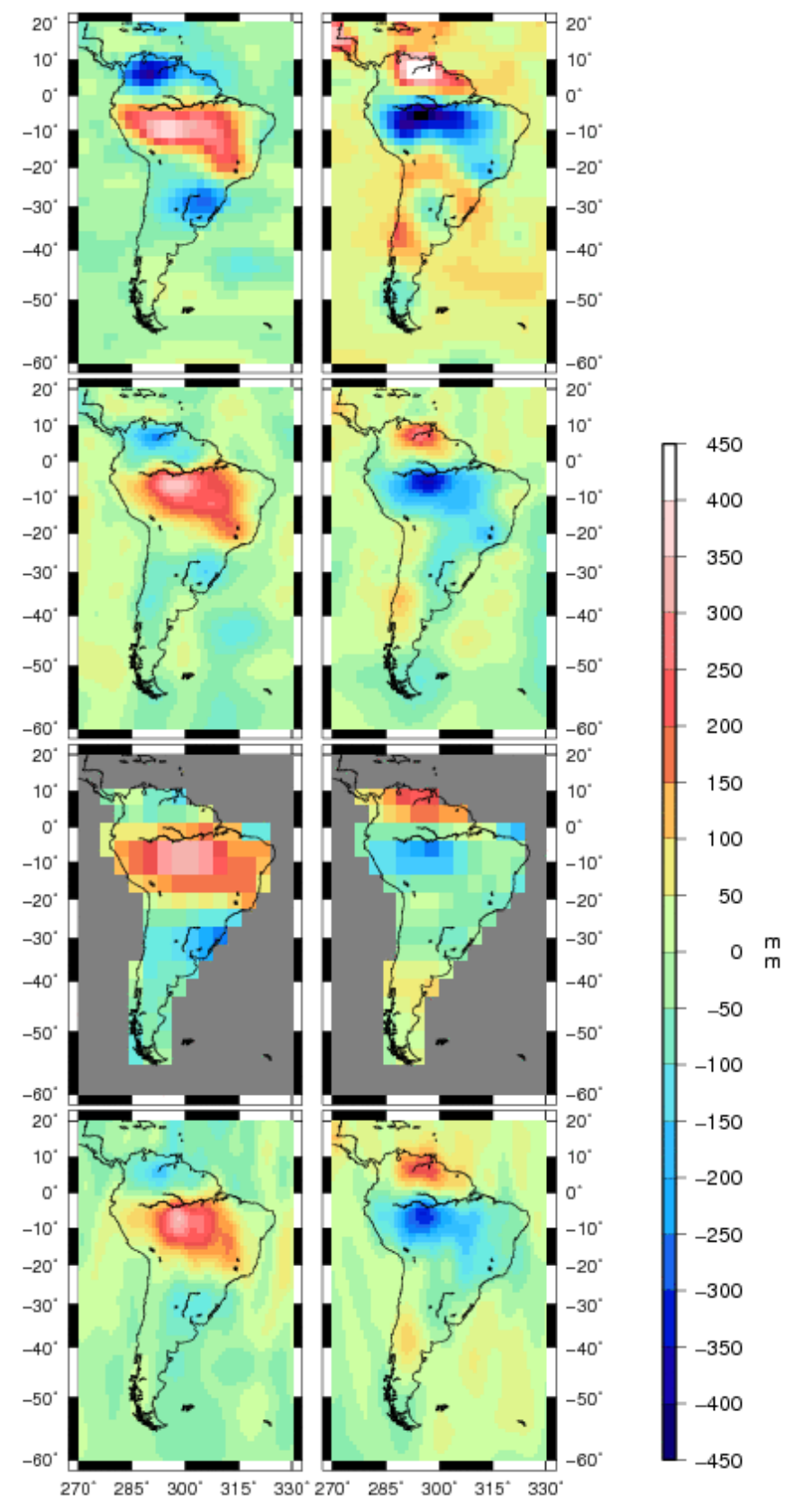
Figure 7

(a)

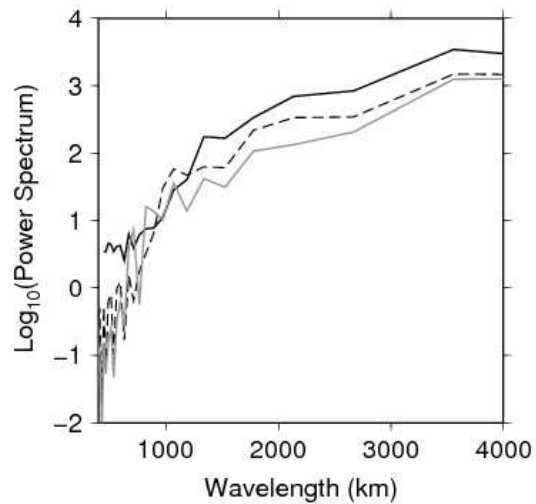

(b)

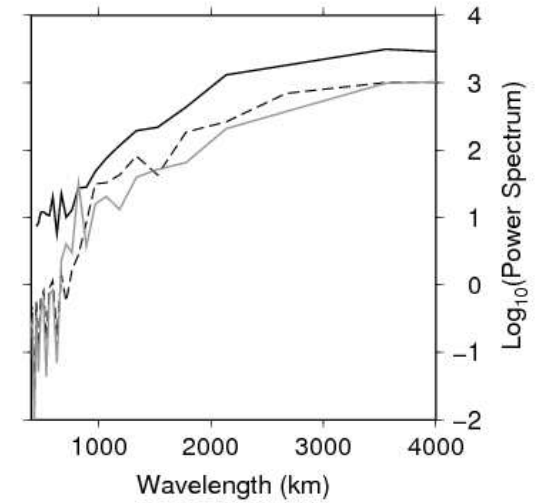


Figure 8

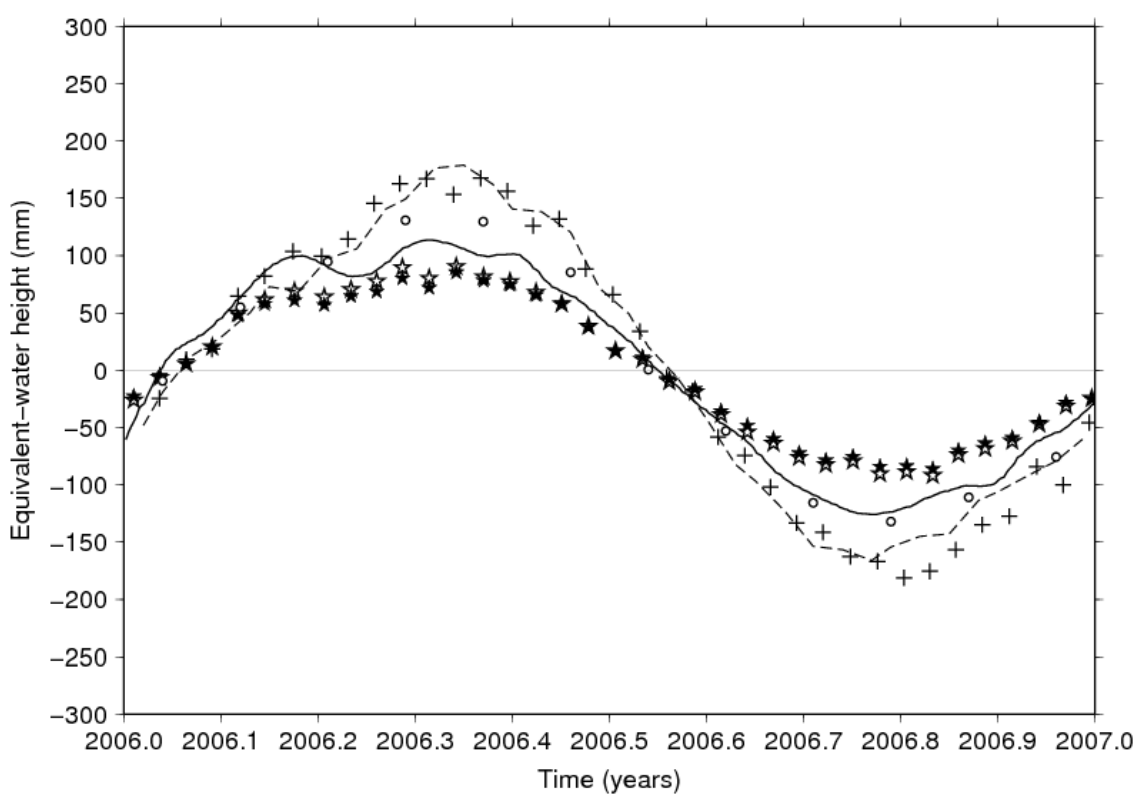


Figure 9

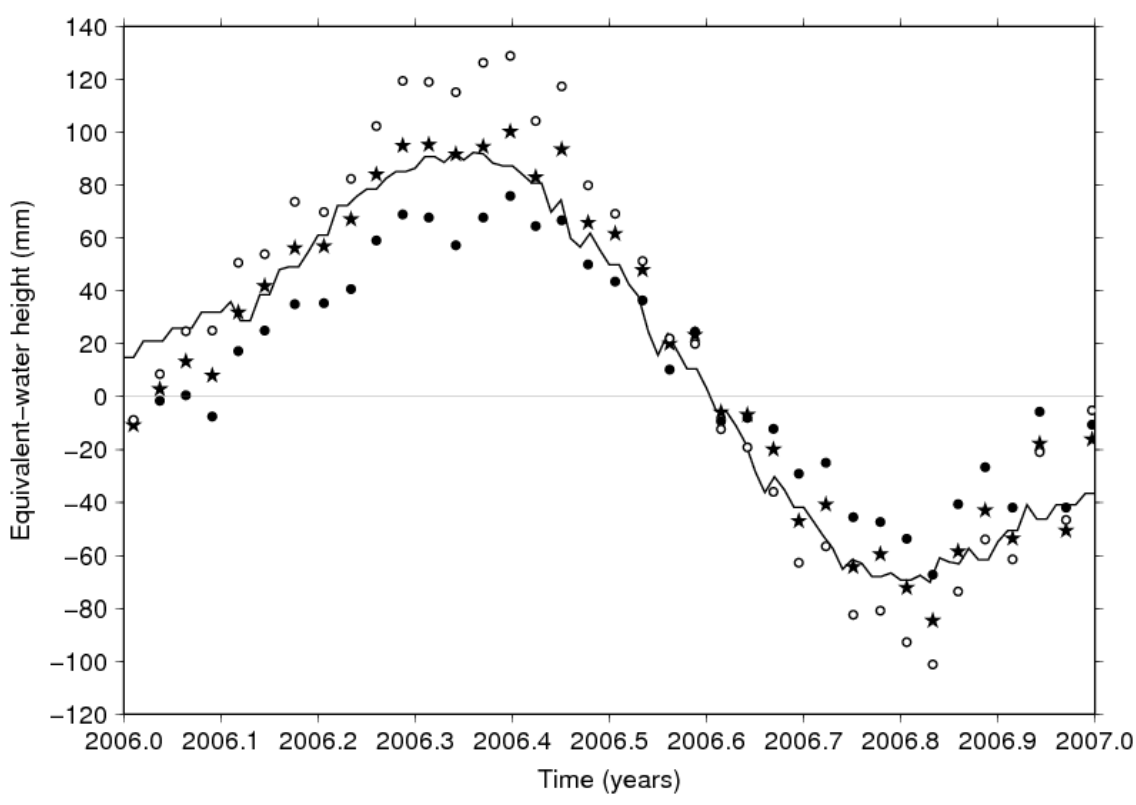


(a)

(b)

(c)

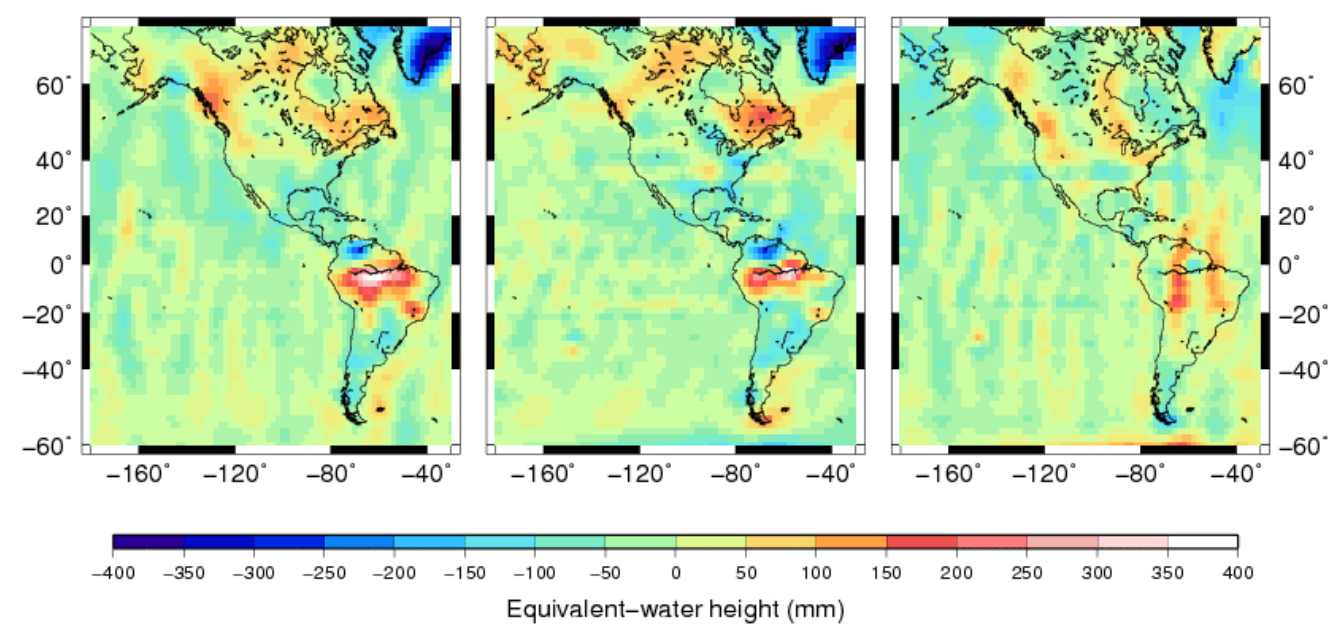


Figure 11

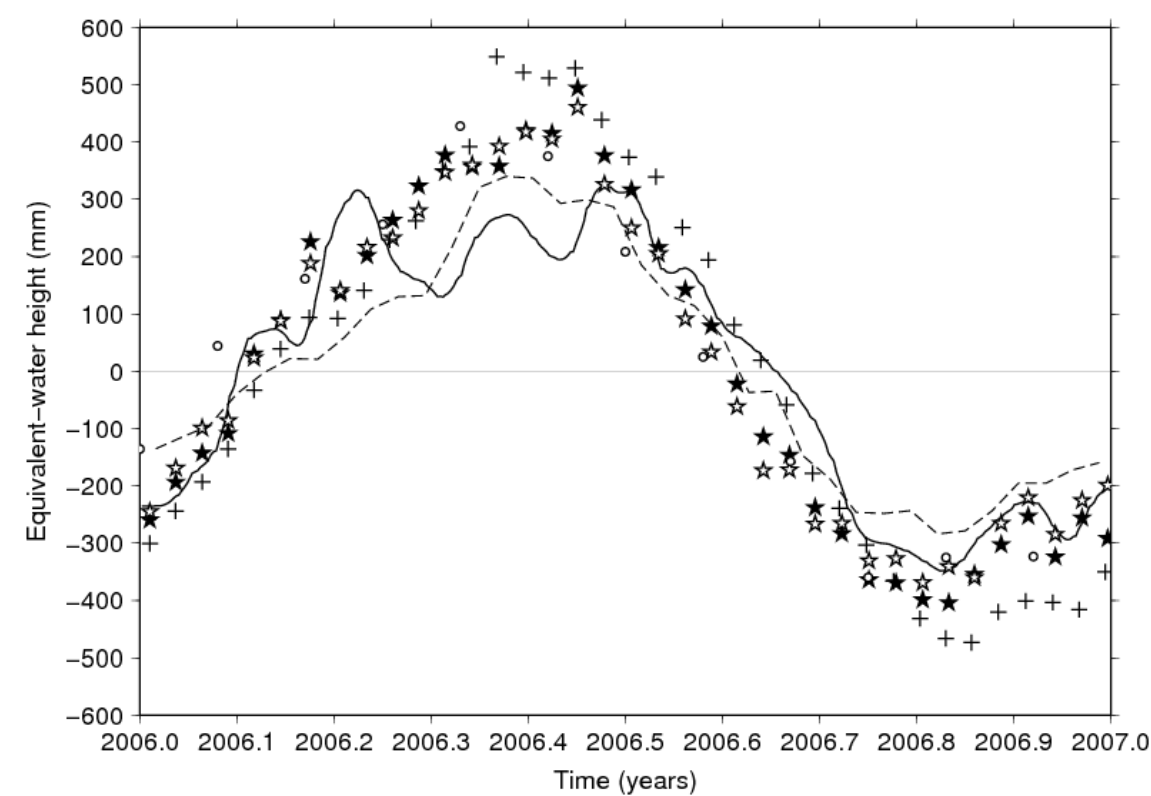




\section{Revised version of ms. GEOP 294 (Surveys in Geophysics):}

"Constrained regional recovery of continental water mass time-variations from GRACE-based geopotential anomalies"

\section{Authors:}

G. Ramillien, L. Seoane, F. Frappart, R. Biancale, S. Gratton, X. Vasseur, S. Bourgogne.

January, 2012.

\section{Dear Editors,}

Would you please find enclosed the revised version of our manuscript. All the minor corrections suggested by the reviewer have been made. As we enclose here an annotated Word file, it is possible to follow easily these corrections in the text.

Our answers to specific reviewer's comments are indicated below.

Best regards,

G. Ramillien and his co-authors.

\section{To the Reviewer and Editors:}

First, we thank the reviewer for his comments that contributed to improve the quality of the manuscript. All his remarks have been considered and corrected (see annotated text).

In particular:

* Paragraph 1.2.3, page 6: The text part presenting the GRACE-based ICA solutions has been rewritten to clarify how they are computed, and which ones are used for comparison with the regional solutions for South America. As mentioned in the text, more details on ICA of the monthly GRACE solutions can be found in Frappart et al., (2010) and Frappart et al., (2011). 
* Loading effects, page 8: a new sentence has been added to precise that elastic compensation can be in the regularization as Legendre polynomials, and thus elastic Love numbers, are introduced. This point is also referred to Eq.24 from Ramillien et al., (2011).

* Eq.11, page 10: we agree the definition of $\mathrm{B}_{\mathrm{i}, \mathrm{j}}$ for the cases 3 and 4 was completely wrong, so that it is now corrected with new formula.

* Spherical harmonics, page 12: Spherical harmonics. We agree about the fact that north-south striping is not only due to the mode of representation in spherical harmonics, but the orbit configuration and time aliasing of short-term phenomena as well. This ambiguous sentence has been simply removed from the text and replaced by the explanation provided by the reviewer.

* Explanation of acronym "MOY" is now given in Eq.11a, page9, and this latter equation is mentioned in the caption of the Figure 3.

--- End of document --- 